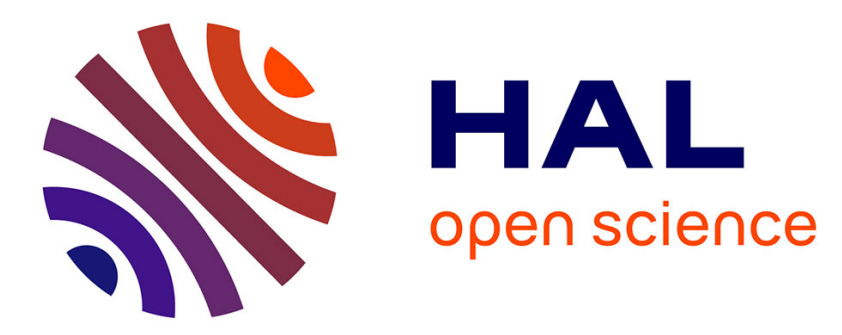

\title{
Prejudice against Muslims: Anxiety as a mediator between intergroup contact and attitudes, perceived group variability and behavioural intentions
}

Paul Hutchison, Harriet E.S. Rosenthal

\section{- To cite this version:}

Paul Hutchison, Harriet E.S. Rosenthal. Prejudice against Muslims: Anxiety as a mediator between intergroup contact and attitudes, perceived group variability and behavioural intentions. Ethnic and Racial Studies, 2010, pp.1. 10.1080/01419871003763312 . hal-00595188

\section{HAL Id: hal-00595188 \\ https://hal.science/hal-00595188}

Submitted on 24 May 2011

HAL is a multi-disciplinary open access archive for the deposit and dissemination of scientific research documents, whether they are published or not. The documents may come from teaching and research institutions in France or abroad, or from public or private research centers.
L'archive ouverte pluridisciplinaire HAL, est destinée au dépôt et à la diffusion de documents scientifiques de niveau recherche, publiés ou non, émanant des établissements d'enseignement et de recherche français ou étrangers, des laboratoires publics ou privés. 


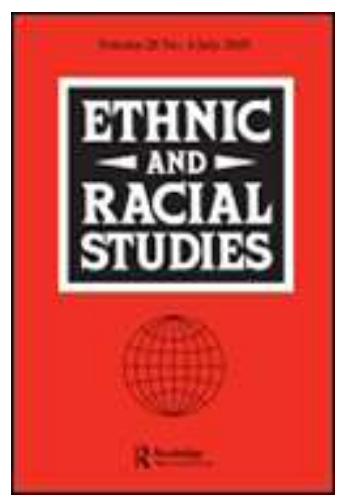

Prejudice against Muslims: Anxiety as a mediator between intergroup contact and attitudes, perceived group variability and behavioural intentions

\begin{tabular}{|r|l|}
\hline Journal: & Ethnic and Racial Studies \\
\hline Manuscript ID: & RERS-2009-0324.R1 \\
\hline Manuscript Type: & Original Manuscript \\
\hline Keywords: & Prejudice, Islam, Attitudes, Racism, Discrimination, Contact \\
\hline \multicolumn{2}{|l}{} \\
\end{tabular}

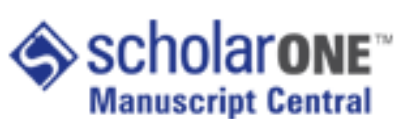


Running header: PREJUDICE AGAINST MUSLIMS

Prejudice against Muslims:

Anxiety as a mediator between intergroup contact and attitudes, perceived group variability

and behavioural intentions

Word count: 7984 


\begin{abstract}
Numerous studies have reported an increase in prejudice against Muslims in recent years. Less research has investigated how this increase might be stemmed and relations between non-Muslims and Muslims improved. In this article, we address prejudice against Muslims from the perspective of intergroup contact theory. We conducted two cross-sectional studies to examine the relationship between nonMuslims' experiences of contact with Muslims and their intergroup anxiety, outgroup attitudes, perceptions of outgroup variability and intergroup behavioural intentions. Study $1(N=58)$ showed that frequent high-quality contact with Muslims predicted more positive outgroup attitudes, more perceived outgroup variability and more positive behavioural intentions. These associations were mediated by intergroup anxiety. Study $2(N=60)$ replicated these effects and additionally showed that anxiety mediates the influence of extended contact on the same outcome measures. Discussion focuses on the implications of the results for strategies aimed at improving relations between non-Muslims and Muslims.
\end{abstract}

Keywords: Prejudice; Islam; Contact; Anxiety; Discrimination; Muslim 
"The prosecution case is that both these defendants...were terrorists motivated by their belief in a fundamental form of Islam. It is essential that the jury that is to try them makes its decisions based solely on the evidence it hears and it is given in this court and not based on any prejudices, beliefs or personal opinions the members of the jury may have."

Mr Justice Mackay -

Addressing potential jurors at the trial of Bilal Abdulla and Mohammed Asha $8^{\text {th }}$ October, 2008

On the $29^{\text {th }}$ June 2007, two car bombs were discovered in London's west end.

Fortunately, attempts to detonate the bombs were unsuccessful. The following day, there was a related unsuccessful suicide bomb attack on Glasgow Airport. While one of the attempted suicide bombers, Kafeel Ahmed, died from injuries sustained during the attack, Bilal Abdulla and Mohammed Asha were charged with conspiracy to murder and to cause explosions with the intent of endangering life. Asha was later found not guilty and acquitted, whereas Abdulla was jailed for a minimum of 32 years for his part in the attempted terrorist attacks. All men were Muslim, and as such, the attacks have been linked to Al Qaeda influenced terrorism (BBC Online 2008).

With the attempted London and Glasgow bombings just two of a number of planned terrorist acts to be linked to violent extremist interpretations of Islam, Muslims worldwide face prejudice in the current climate (as stressed by Mr Justice Mackay). ${ }^{1}$ In the USA, following the events of September $11^{\text {th }}, 2001$, hate crimes against $\mathrm{Arabs}^{2}$ and Muslims increased by $1700 \%$ (Federal Bureau of Investigation crime statistics, cited in Sheridan and Gillett 2005). In Europe, significant increases 
in anti-Islamic prejudice were reported in all member states (Allen and Nielsen 2002). Similarly, a study of British Muslims revealed that post-2001, levels of implicit and indirect discrimination increased by 83 per cent and experiences of overt discrimination by 7 per cent (Sheridan 2006).

Similar trends have been reported in research within social psychology. Echebarria-Echabe and Fernández-Guede (2006) measured attitudes towards Arabs before and after the Madrid train bombings of 2004, finding that anti-Arab attitudes increased following the attack. Nosek et al. (2007) found stronger positive implicit and explicit preference for 'other' names (deemed unfamiliar for US participants) compared to Arab-Muslim names. Park, Felix, and Lee (2007) found an implicit preference for white and black names compared to Arab-Muslim names and this preference was unaffected by the participants' ethnicity (black; white; Hispanic; Asian-American). Park et al. (2007) suggested that the negative view of Muslims stems from exposure to information linking Muslims to terrorism, finding the effect abated when participants read a positive article about Muslim culture compared to those reading a neutral or negative article. Thus, research appears to support the view of Mr Justice Mackay: Muslims are currently perceived in a negative light.

In this article, we address prejudice against Muslims from the perspective of one of social psychology's most enduring strategies for improving intergroup relations: the intergroup contact hypothesis (Allport 1954). We conducted two studies to examine the relationship between non-Muslim respondents' experiences of contact with Muslims and their intergroup anxiety, outgroup attitudes, perceptions of outgroup variability and intergroup behavioural intentions. Study 1 investigated the combined effect on these variables of contact quantity and contact quality. In Study 2, 
we broadened our investigation to additionally examine extended contact (Wright et al. 1997).

Intergroup contact hypothesis

The intergroup contact hypothesis (Allport 1954) proposes that contact with individual members of an outgroup can improve intergroup attitudes and reduce prejudice. Allport (1954) argued that for contact to be effective in reducing prejudice at least four situational conditions must be met. First, the contact must occur in a situation of equal status. Second, the groups must have shared goals. Third, attainment of such goals must involve intergroup cooperation. Finally, the initiative must have the support of relevant institutions and authorities. Pettigrew (1998) later proposed an additional key condition, arguing that the contact situation must allow the opportunity for friendships to develop.

Since its original formulation, a considerable amount of research has investigated whether the proposed prerequisite conditions are sufficient, or indeed necessary, for contact to reduce prejudice. In a meta-analysis of 515 laboratory and field studies, Pettigrew and Tropp (2006) demonstrated that even when the proposed prerequisite conditions are not in place, contact reduces prejudice. However, in those studies with optimal contact conditions, even lower levels of prejudice were reported.

The majority of studies in the intergroup contact framework have investigated the effects of contact on attitudes or other affective/evaluative outcome measures. This has been extended in recent years to additionally examine perceived group variability, which refers to the extent to which individual group members are seen as similar or distinct from one another (Park and Judd 1990). Research suggests that people often perceive outgroups as more homogenous and undifferentiated than their ingroup (e.g., Quattrone and Jones 1980; Ostrom and Sedikides 1992). Although 
there is evidence to suggest that perceived homogeneity may, in certain situations, be valued (Hutchison et al. 2006), perceiving the outgroup as homogeneous is more often associated with negative stereotypes and unfavourable attitudes (Allport 1954).

Several studies have demonstrated that frequent high-quality contact with outgroup members can increase the perception of outgroup variability. Islam and Hewstone (1993) investigated contact between Muslims and Hindus in Bangladesh and found that the more positive contact with outgroup members that respondents experienced, the more favourable their attitudes and the greater their perceptions of outgroup variability. Paolini et al. (2004) investigated contact between Catholics and Protestants in Northern Ireland and found that contact was negatively associated with prejudice and positively associated with perceived outgroup variability. Along similar lines, Voci and Hewstone (2003) investigated contact between Italian students and African immigrants and found that contact was positively associated with more positive outgroup attitudes and more perceived outgroup variability. As Voci and Hewstone argued, while an increase in perceived outgroup variability does not represent a decrease in actual prejudice, it may act as a step towards reducing negative outgroup stereotypes and improving intergroup relations.

As well as outgroup attitudes and perceived outgroup variability, in the present studies we also investigated the relationship between contact and intergroup behavioural intentions. Research has consistently demonstrated that behavioural intentions are a stronger predictor of a range of behaviours than are general attitudes (e.g., Albarracin et al. 2001). A meta-analysis conducted by Sutton (1998) confirmed that behavioural intentions generally predict between 19 and 38 per cent of the variance in actual behaviour, leading the author to conclude that intentions to engage in a particular behaviour are both the immediate antecedent and single best predictor 
of actual behaviour. Despite this long-established link between behavioural intentions and actual behaviour, only a few studies have examined the link between intergroup contact and intergroup behavioural intentions.

In one study, Viki et al. (2006) investigated contact with the police among a sample of students in the UK and found that the better the quality of contact that Black respondents experienced with the police, the more positive their attitudes towards assisting the police and the greater their intentions to cooperate with police investigations. Along similar lines, Tam et al. (2009) investigated contact between Catholics and Protestants in Northern Ireland and found that frequent high-quality contact predicted greater intergroup trust, more favourable outgroup attitudes and more positive intergroup behavioural "tendencies" (e.g., the intention to find out more about the outgroup). The present research extends this previous work by investigating the role of intergroup anxiety as a mediator between non-Muslim respondents' experiences of contact with Muslims and their behavioural intentions towards Muslims.

\section{Intergroup anxiety as a mediator of contact effects}

Having confirmed that intergroup contact can reduce prejudice, recent research has attempted to establish mediators of the contact effect. One mediator receiving considerable attention is intergroup anxiety, which refers to the negative affective feeling often experienced during actual or anticipated intergroup contact (Stephan and Stephan 1985). According to Stephan and Stephan (1985), intergroup anxiety can result from negative outcome expectancies - e.g., expectations that intergroup interactions will lead to embarrassment or rejection or that one's behaviour will come across as prejudiced (Plant and Devine 2003). Situations especially likely to generate intergroup anxiety include those where there has been little or no previous 
contact, where negative stereotypes are prevalent, or where there is a sense of threat or danger from the outgroup (Stephan and Stephan 1985; Stephan and Renfro 2002). Research suggests that anxiety of this type can suppress the potential beneficial effect of contact in reducing prejudice. It can also lead to hostility and avoidance of contact situations (Plant and Devine 2003; Hutchison et al. in press) and an increased reliance on stereotypes (Stephan and Stephan 1985; Wilder and Shapiro 1989). Following positive contact, however, anxiety about future intergroup interactions is often reduced (e.g., Islam \& Hewstone, 1993; Bousfield and Hutchison, 2010).

Although we are aware of no research that has investigated whether intergroup anxiety mediates between contact and behavioural intentions, anxiety has previously been established as a mediator of the effect of contact on outgroup attitudes and perceived outgroup variability. Voci and Hewstone (2003) found that anxiety mediated the positive effect of contact on Italians' attitudes towards African immigrants. In their study of contact between Muslims and Hindus, Islam and Hewstone (1993) found that anxiety mediated the positive effect of contact on outgroup attitudes and perceived outgroup variability. Similarly, in their study of contact between White schoolchildren and South Asians in the UK, Turner, Hewstone and Voci (2007) showed that anxiety, along with self-disclosure, mediated the positive association between contact and outgroup attitudes.

The present research extends this previous work by investigating whether variations in intergroup anxiety mediate not only the influence of intergroup contact on outgroup attitudes and perceived outgroup variability, but also the proposed positive effect of contact on behavioural intentions. Examining the role of intergroup anxiety in the context of relations between non-Muslims and Muslims is especially important in light of numerous reports suggesting that prejudice against Muslims has 
gathered momentum in recent years, especially since the events of September $11^{\text {th }}$ 2001 and claims that it is sustained by (often media-generated) anxieties about issues related to national security, asylum seekers, and the potential for further 'homegrown' terrorist attacks (Phillips 2006; Sheridan 2006).

In the present research, we investigate whether different types of contact with Muslims are associated with non-Muslim respondents' anxiety about interacting with Muslims and whether this anxiety in turn influences their outgroup attitudes, perceptions of outgroup variability and intergroup behavioural intentions.

\section{The current research}

We conducted two studies with samples of non-Muslims in London to investigate the relationship between their experiences of contact with Muslims and their intergroup anxiety, outgroup attitudes, perceptions of outgroup variability and intergroup behavioural intentions. Study 1 investigated the effects on these variables of contact quantity and contact quality. In Study 2, we broadened our investigation to additionally examine extended contact. The extended contact hypothesis (Wright et al. 1997) proposes that knowing an ingroup member has an outgroup friend can lead to more favourable outgroup attitudes, and several studies have illustrated the effectiveness of extended contact in improving intergroup attitudes and increasing perceptions of variability among outgroup members (Wright et al. 1997; Liebkind and McAlister 1999; Paolini et al. 2004; Turner et al. 2007; Turner et al. 2008). In Study 2, as well as outgroup attitudes and perceived outgroup variability, we also investigated the relationship between extended contact and non-Muslims' behavioural intentions towards Muslims.

\section{Study 1}


Study 1 examined the relationship between non-Muslim respondents' experiences of contact with Muslims and their perceptions of and attitudes and behavioural intentions towards Muslims. We examined the effects on these variables of contact quantity and contact quality. Drawing on the lines of research described above, it was predicted that more frequent high-quality contact with Muslims would be associated with more positive outgroup attitudes, more perceived outgroup variability and more positive behavioural intentions towards Muslims. Additionally, it was predicted that the positive effect of contact on each of these outcome variables would be mediated by variations in intergroup anxiety.

\section{$\underline{\text { Method }}$}

\section{Participants}

Fifty-eight students at a London university participated on a voluntary basis. None of the participants were Muslim. Twenty-seven were male and thirty-one were female. Ages ranged from 19 to 62 with a mean age of 28.35 years $(S D=9.88)$. As neither gender nor age had an effect in the analyses reported below, these variables are not considered further. ${ }^{3}$

\section{Materials and procedure}

Participants were approached on a university campus and asked to participate in a study investigating how people form impressions of others. ${ }^{4}$ Those who agreed were handed a questionnaire containing all instructions and measures, which were presented in the same order as described below. Unless stated otherwise, responses to all items were recorded on a scale ranging from 1 (strongly disagree) to 5 (strongly agree). After they had completed the questionnaire, participants were thanked and debriefed. 
Intergroup contact measures. A single item was used to measure contact

quantity. Participants were asked to write a number in the space provided to indicate, on average, how many Muslims they come into contact with in a typical week.

Contact quality was assessed by asking participants to rate the quality of contact they have with Muslims on a scale ranging from 1 (very bad) to 5 (very good). Following the procedure adopted in previous contact studies (e.g., Voci and Hewstone 2003), we calculated a multiplicative index of contact quantity and contact quality to obtain a single intergroup contact score. A higher score on this index indicates a higher frequency of high-quality intergroup contact.

Outgroup attitudes. Participants indicated their attitudes towards Muslims using two items: "I like Muslims" and "I prefer to spend time with non-Muslims than Muslims". They were informed that responses should reflect their feelings about Muslims in general, not necessarily those with whom they have contact with. The second item was reverse-scored and combined (averaged) with the first item to form a single outgroup attitude score $(r=.49)$. A higher score indicates a more positive attitude.

Perceived outgroup variability. Two items measured the perception of variability among Muslims: "I feel that all Muslims are similar," and "I feel that there are different kinds of people among Muslims". The first item was reversescored and combined with the second item to form a single perceived outgroup variability score $(r=.79)$. A higher score indicates more perceived outgroup variability.

Intergroup behavioural intentions. Two items measured the extent to which participants would intentionally engage in positive behaviour towards Muslims: "I would help a Muslim if he or she was being discriminated against," and "I would 
donate money to organizations whose aim is to reduce prejudice against Muslims." These items were combined to form a single intergroup behavioural intentions score $(r=.78)$. A higher score indicates more positive intergroup behaviour intentions. Intergroup anxiety. Two items measured the extent to which participants felt anxious about coming into contact with Muslims: "I feel anxious when I come into contact with Muslims," and "I feel nervous when I come into contact with Muslims." These items were combined to form a single intergroup anxiety score $(r=.83)$. A higher score indicates more intergroup anxiety.

\section{$\underline{\text { Results and Discussion }}$}

\section{Correlation analyses}

Table 1 depicts the means, standard deviations and correlations among the measures. As indicated in this table, contact quantity, contact quality and the multiplicative intergroup contact index (referred to from this point on as intergroup contact) were all related to the outcome measures in ways predicted by contact theory (Allport 1954). All three contact measures were positively associated with outgroup attitudes, perceived outgroup variability and intergroup behavioural intentions, and were negatively associated with intergroup anxiety. Additionally, intergroup anxiety was negatively related to outgroup attitudes, perceived outgroup variability and intergroup behavioural intentions.

Table 1 about here

\section{Mediation analyses}

We conducted mediation analyses to assess whether the associations between intergroup contact and the outcome measures were mediated by variations in 
intergroup anxiety. ${ }^{5}$ Following procedures outlined by Baron and Kenny (1986), this involved (1) regressing each of the outcome measures on the predictor variable (intergroup contact), (2) regressing the mediator (intergroup anxiety) on the predictor variable, and (3) regressing each of the outcome measures in turn on the predictor variable and the mediator. For mediation to be present there must be a significant relationship between the mediator and the predictor variable, and when the outcome measure is regressed on both the mediator and the predictor variable, a previously significant relationship between the predictor and outcome measure should be significantly reduced (partial mediation) or rendered non-significant (full mediation).

Table 2 about here

The regression analyses confirmed the direct associations between the variables reported in Table 1. Indirect associations between the predictor and outcome measures (entered with the mediator) and between the mediator and the outcome measures (entered with the predictor) are presented in Table 2. As this table indicates, previously significant relationships between intergroup contact and each of the outcome measures were reduced to a non-significant level (perceived outgroup variability, intergroup behavioural intentions) or significantly reduced (outgroup attitudes) when intergroup anxiety was also included as a predictor in the analysis. Sobel tests (Preacher and Leonardelli 2001) confirmed that these reductions were significant (outgroup attitudes: $z=2.54, p=.011$; perceived outgroup variability: $z=$ 2.69, $p=.007$; intergroup behavioural intentions: $z=3.53, p<.001)$. In all cases, intergroup anxiety remained a significant predictor when intergroup contact was also included as a predictor in the analysis. 
In sum, the results confirm that the association between non-Muslim respondents' experiences of contact with Muslims and their perceptions of and attitudes and behavioural intentions towards Muslims was mediated by their anxiety about interacting with Muslims. The results are consistent with previous research which has shown that intergroup anxiety mediates the positive association between contact and outgroup attitudes and between contact and perceived outgroup variability (see Pettigrew and Tropp 2008). In addition, the findings extend the role of anxiety as a mediator of contact effects on outgroup attitudes and perceived outgroup variability, to also include intergroup behavioural intentions. We conducted a second study to test the robustness of these effects and also to investigate whether extended contact (Wright et al. 1997) with Muslims might have similar positive effects on non-Muslim respondents' perceptions of and attitudes and behavioural intentions towards Muslims.

\section{Study 2}

Despite the obvious benefits of contact in reducing prejudice, a limitation with the contact hypothesis in its original formation (Allport 1954) is the requirement that members of opposing groups must have the opportunity for positive contact in the first place. In some situations, this may be impractical or even impossible. There are numerous examples of groups with little or no opportunities to engage in meaningful high-quality contact: for example, Israelis and Palestinians in the Middle East and Catholics and Protestants in parts of Northern Ireland. Likewise, despite being one of the most multicultural cities worldwide, some reports suggest that parts of London (especially East London where the research was conducted) are becoming increasingly segregated along religious and ethnic lines (Community Cohesion Review Team 2001; BBC Online 2006; Phillips 2006). Although this assumption has 
been strongly contested (e.g., Finney and Simpson 2009), it is nonetheless worthwhile exploring whether direct contact is actually necessary to reduce prejudice, or whether more vicarious forms of intergroup relationships might have a similar positive effect on relations between non-Muslims and Muslims. Therefore, in Study 2, along contact quantity and contact quality, we additionally included a measure of extended contact (Wright et al. 1997).

The extended contact hypothesis (Wright et al. 1997) proposes that knowing that an ingroup member has a positive relationship with an outgroup member can improve attitudes towards the outgroup as a whole and set the grounds for more positive intergroup relations. The benefits of extended contact in improving intergroup attitudes and increasing the perception of outgroup variability are now well established (Wright et al. 1997; Liebkind and McAlister 1999; Paolini et al. 2004; Turner et al. 2007; Turner et al. 2008). As well as attitudes towards Muslims and perceived outgroup variability, in Study 2 we also examined the effects of extended contact on non-Muslims' behavioural intentions towards Muslims. Few studies have investigated the link between intergroup contact (direct or extended) and intergroup behavioural intentions, and to our knowledge, none have examined whether intergroup anxiety mediates the extended contact-behavioural intention relationship. We tested this prediction in Study 2 along with seeking to replicate the effects obtained in Study 1.

\section{$\underline{\text { Method }}$}

\section{Participants}

Sixty non-Muslim students at a London university participated on a voluntary basis. None had participated in Study 1. Twenty-seven were male and thirty-three were female. The age range was from 18 to 65 , with a mean of 25.5 years $(S D=8.44)$. As 
neither gender nor age had an effect in the analyses, we do not discuss these variables further.

\section{Materials and procedure}

Participants were recruited on a university campus. ${ }^{6}$ All participants were handed a questionnaire containing the instructions and measures, which were presented in the same order as described below. Unless stated otherwise, responses to all items were recorded on 5-point Likert-type scales. A debriefing information sheet was handed to each participant at the end of the study.

Intergroup contact measures. Participants completed the same measures of contact quantity and contact quality from Study 1. As in Study 1, we computed a multiplicative index of contact quantity and contact quality to provide a single intergroup contact score. Extended contact was measured by asking participants to write a number in the space provided to indicate how many of their close friends or relatives have Muslim friends, with a higher number indicating more extended contact.

Outgroup attitudes. Participants rated Muslims using six pairs of bipolar adjectives, which were separated by a 5-point scale. The adjective pairs were the same as those used by Wright et al. (1997) in their research on extended contact: warm-cold, negative-positive, friendly-hostile, respect-contempt, suspicious-trusting and admiration-disgust. Responses were scored such that a higher score indicates a more positive outgroup attitude. The items were then combined to form a single outgroup attitude score $(\alpha=.90)$. We used this measure rather than the one in Study 1 because the items in the previous measure may be more susceptible to socially desirable responding. 
Perceived outgroup variability. The same two items from Study 1 were used to measure the perception of variability among Muslims $(\alpha=.71)$. A higher score indicates more perceived outgroup variability.

Intergroup behavioural intentions. Four items measured participants' behavioural intentions towards Muslims. The first two items were the same as in Study 1. The other two items were: "I want to learn more about Muslim culture," and "I would like to visit a Muslim country." We included these additional items to reflect the different ways that pro-social attitudes towards Muslims might be expressed. These four items were combined to form a single intergroup behavioural intentions score $(\alpha=.66)$. A higher score indicates more positive intergroup behaviour intentions.

Intergroup anxiety. Four items measured the extent to which participants felt anxious about coming into contact with Muslims. Two items were the same as those used in Study 1. The two additional items were: "I feel relaxed when I come into contact with Muslims," (reversed) and "I feel threatened when I come into contact with Muslims”. All four items were combined to form a single intergroup anxiety score $(\alpha=.95)$. A higher score indicates more intergroup anxiety.

\section{$\underline{\text { Results and Discussion }}$}

\section{Correlation analyses}

Table 3 depicts the means, standard deviations and correlations among the measures. As shown in this table, the contact measures were all associated with the outcome measures in expected directions. Contact quantity, contact quality, the intergroup contact index and extended contact were all positively associated with outgroup attitudes, perceived outgroup variability and intergroup behavioural intentions, and were all negatively associated with intergroup anxiety. Additionally, intergroup 
anxiety was negatively associated with outgroup attitudes, perceived outgroup variability and intergroup behavioural intentions.

Table 3 about here

\section{Mediation analyses}

As in Study 1, a series of regression analyses were computed to examine the role that intergroup anxiety played in mediating between different types of intergroup contact and the various outcome measures (Baron and Kenny 1986). ${ }^{5}$ The regression analyses confirmed the direct associations between the variables reported in Table 1 . Indirect associations between the predictor and outcome measures (entered with the mediator) and between the mediator and the outcome measures (entered with the predictor) are presented in Table 4. As this table indicates, previously significant relationships between intergroup contact and the outcome measures were reduced to a non-significant level (perceived outgroup variability, intergroup behavioural intention) or significantly reduced (outgroup attitudes) when intergroup anxiety was included as a predictor in the analyses. Sobel tests (Preacher and Leonardelli 2001) confirmed that these reductions were significant (outgroup attitudes: $z=2.46, p=.02$; perceived outgroup variability: $\mathrm{z}=2.15, p=.03$; intergroup behavioural intentions: $z$ $=2.17, p=.03)$. In all cases, intergroup anxiety remained a significant predictor when intergroup contact was also included in the analysis.

A similar pattern emerged for the extended contact measure. The previously significant associations between extended contact and the outcome measures were reduced to a non-significant level when intergroup anxiety was also included as a predictor (outgroup attitudes: $z=2.70, p=.007$; perceived outgroup variability: $z=$ 
2.52, $p=.01$; intergroup behavioural intentions: $z=2.54, p=.01)$. In all cases, the association between intergroup anxiety and the outcome measure in question remained significant when extended contact was also included as a predictor.

Table 4 about here

In sum, the results from Study 2 replicated the findings of Study 1, showing that anxiety about interacting with Muslims mediates the positive relationship between non-Muslim respondents' previous experiences of contact with Muslims and their perceptions of and attitudes and behavioural intentions towards Muslims. Moreover, replicating the direct contact effects obtained in both studies, the results confirm that intergroup anxiety also mediates the effect of non-Muslim respondents' experiences of extended contact with Muslims on the various outcome measures. To our knowledge, this is the first study to demonstrate that variations in intergroup anxiety mediate the association between extended contact and intergroup behavioural intentions.

\section{General Discussion}

Numerous studies point to a widespread increase in prejudice against Muslims in recent years. Relatively less empirical research has considered how this apparent increase may be stemmed and relations between non-Muslims and Muslims improved. The present research addressed prejudice against Muslims from the perspective of intergroup contact theory (Allport 1954). We conducted two studies with non-Muslim respondents to examine the relationship between their previous experiences of contact with Muslims and their perceptions of and attitudes and behavioural intentions towards Muslims. Results supported our predictions. In both 
studies, a greater amount of high-quality contact with Muslims was associated with more positive attitudes towards Muslims, the perception of Muslims as distinct individuals rather than a homogeneous entity, greater intentions to behave positively towards Muslims, and less anxiety about coming into contact with Muslims. In Study 2, these findings were additionally replicated for non-Muslims' extended contact with Muslims.

Intergroup anxiety, in turn, was examined as a mediator between contact (both direct and extended) and outgroup attitudes, perceived outgroup variability and intergroup behavioural intentions. Greater anxiety about coming into contact with Muslims was associated with a lower amount of quality contact with Muslims and a lower amount of extended contact with Muslims. Greater intergroup anxiety was also associated with more negative attitudes toward Muslims, lower perceived variability among Muslims, and less positive behavioural intentions toward Muslims. Further analysis revealed that variations in intergroup anxiety mediated the relationship between contact (direct and extended) and outgroup attitudes, perceived outgroup variability and intergroup behavioural intentions.

Our results are consistent with previous studies that have demonstrated that anxiety mediates the positive effect of contact (quantity and quality) on outgroup attitudes (for a review, see Pettigrew and Tropp 2008). In addition, Study 2 adds further support to the recent extension of this finding in terms of extended contact (Turner et al. 2008), by establishing that non-Muslims respondents' anxiety about interacting with Muslims mediates between their experiences of extended contact with Muslims and their attitudes towards Muslims generally.

The studies have also confirmed that the level of anxiety experienced by nonMuslim respondents about interacting with Muslims mediates the link between their 
previous experiences of contact with Muslims (direct and extended) and their perceptions of variability among Muslims. The finding that extended contact resulted in the perception of Muslims as more variable, and that anxiety mediated this effect, is in line with Paolini et al. (2004), who examined direct and indirect cross-group friendships between different religious groups in Northern Ireland, finding that intergroup anxiety mediated the relationship between direct and indirect friendship and perceived group variability. Finding that contact with Muslims is associated with more perceived variability among Muslims is especially important in the current climate, given that the image of Muslims generated and sustained in the media and much political discourse (Merskin 2004) is of a homogenous community aspiring towards a single political aim (Afshar, Aitken and Franks 2005). The results from the present studies suggest that frequent positive contact and extended contact with Muslims may go some way towards changing this perception of homogeneity held by many non-Muslims, which in turn may pave the way for more positive and constructive relations between non-Muslims and Muslims generally.

Perhaps the most important finding of the studies reported here is the link between contact and intergroup behavioural intentions. A behavioural intention can be defined as the motivational factor behind a particular behaviour, which dictates whether the behaviour will be performed or not (Ajzen 1991). As such, linking contact to behavioural intentions can be seen as a step closer towards linking contact to actual behaviour. Recent research has begun to examine this link (Viki et al. 2006; Tam et al. 2009; Bousfield and Hutchison 2010; Hutchison et al., in press), and the studies reported here add further support to the claim that increased contact with outgroup members is associated with an intention to behave positively towards that outgroup. Finding that intergroup anxiety mediated this relationship offers further 
support for the role of intergroup anxiety as a mediator in the contact literature, extending this to include intergroup behavioural intentions. Given the established link between behavioural intentions and actual behaviour, this finding has real implications for predicting actual behaviour towards Muslims. Future research is needed to address this point further, examining whether strategies aimed at promoting different types of contact between non-Muslims and Muslims can affect actual pro-social behaviour towards Muslims, for instance, helping Muslims experiencing discrimination or pledging support for concrete policies or interventions designed to accomplish racial, ethnic and religious integration (see also Dixon, Durrheim and Tredoux 2005).

Although our research provides consistent support for our hypotheses, there are limitations with the current studies that future research should seek to address. Both studies were conducted with students from the same university campus in East London. The university has one of the lowest ratios of non-Muslim to Muslim students in the UK and is located in the borough of Tower Hamlets, which has the highest proportion of Muslims of all local authority districts in the UK at 36 per cent (2001 Census statistics, cited in Greater London Authority 2006, p. 11). It is likely that non-Muslim students at this university have more contact with Muslims than non-Muslims at other UK universities and these different experiences may result in different attitudes, perceptions, and behavioural intentions than for non-Muslim students at other universities. The current research should therefore be extended to include non-Muslim students at more 'typical' UK universities and in addition further research using non-student samples would be desirable. It is possible that non-Muslim students in general have different experiences with Muslims than nonstudents and, therefore, different expectations and attitudes. Indeed, the variability of 
the quantity, quality and extended contact of students is likely to be lower for students than for non-students, especially considering the students at the current university are likely to have a high level of contact with Muslims. Therefore the external validity of our findings may be limited.

Another limitation of the current research is that both studies used a crosssectional design, making it difficult to infer causality. It is theoretically possible that those respondents in our research with more favourable attitudes and intentions towards Muslims were more likely to seek out and engage in positive contact with Muslims. Indeed, previous research has demonstrated that negative outgroup attitudes restrict intergroup contact at the same time contact improves attitudes (e.g., Binder et al. 2009). It is important, therefore, for future research to use longitudinal and experimental designs in order that more conclusive inferences about causality may be established.

Future research should also investigate whether other variables mediate the relationship between contact and intergroup behavioural intentions. Our research focused on the mediational role of intergroup anxiety, whereas previous research has shown that there are many additional mediators of the relationship between contact and prejudice, such as self-disclosure (Turner et al., 2007), empathy and perspective taking (Tam et al. 2006), trust (Tam et al. 2009), and knowledge of the outgroup (Stephan and Renfro 2002). In their meta-analysis of mediators of the contact effect, Pettigrew and Tropp (2008) suggested a causal sequence whereby initial intergroup anxiety must first be reduced via intergroup contact before other such additional variables can effectively contribute to prejudice reduction. Future research should examine whether this proposed causal sequence exists in the context of relations between non-Muslims and Muslims. 
Despite these limitations, our study is important for establishing that although prejudice against Muslims (or Islamophobia) is often perceived as different from other types of prejudice (e.g., Cole, 2009), it can be reduced in the same ways that other types of prejudice can. Finding that extended contact is associated with the same positive outcomes as direct contact suggests that actual contact between nonMuslims and Muslims may not be necessary to reduce prejudice. Instead, our results suggest that anti-Muslim prejudice could be reduced by emphasising Muslim friendships held by other non-Muslims. Along these lines, Cameron and colleagues (Cameron, Rutland and Brown, 2007) found that schoolchildren's attitudes towards refugees in the UK improved following an intervention which involved reading stories about cross-group friendships. Likewise, Turner and colleagues (Turner, Crisp, and Lambert, 2007) demonstrated that simply imagining contact with members of an outgroup can improve intergroup attitudes and reduce prejudice. Together, these findings should be of interest to those involved in the design of strategies and interventions aimed at improving relations between non-Muslims and Muslims. 


\title{
References
}

AFSHAR, H., AITKEN, R. and FRANKS, M. 2005 'Feminisms, Islamophobia and identities', Political Studies, vol. 53, 262-83

\author{
AJZEN, I. 1991 'The theory of planned behavior', Organizational Behavior and \\ Human Decision Processes, vol. 50, 179-211
}

ALBARRACIN, D. et al. 2001 'Theories of reasoned action and planned behavior as models of condom use: A meta-analysis', Psychological Bulletin, vol. 127, no. 1, $142-61$
ALLEN, C. and NIELSEN, J. S. 2002 Summary report on Islamophobia in the EU after 11 September 2001. Vienna, Austria: European Monitoring Centre on Racism and Xenophobia

\begin{abstract}
ALLPORT, G. W. 1954 The nature of prejudice. Reading, MA: Addison-Wesley
BARON, R. M. and KENNY, D. A. 1986 'The moderator-mediator variable distinction in social psychological research: Conceptual, strategic, and statistical considerations' Journal of Personality and Social Psychology, vol. 51, no. 6, 1173 82
\end{abstract}

BBC ONLINE 2006 'Parallel lives?', Retrieved 23 June 2009 from: http://www.bbc.co.uk/lancashire/content/articles/2006/11/21/parallel_lives_feature.s html

BBC ONLINE 2008. 'The men accused of car bomb plot', Retrieved 9 October 2008 from: http://news.bbc.co.uk/1/hi/uk/7662134.stm

BINDER, J. et al. 2009 'Does contact reduce prejudice or does prejudice reduce contact? A longitudinal test of the contact hypothesis in three European countries', Journal of Personality and Social Psychology, vol. 96, no. 4, 843-56 
BOUSFIELD, C. and HUTCHISON, P. 2010 'Contact, anxiety, and young people's attitudes and behavioural intentions towards the elderly', Educational Gerontology BROWN, R. and HEWSTONE, M. 2005 'An integrative theory of intergroup contact', in M. Zanna (ed), Advances in experimental social psychology, vol. 37, San Diego, CA: Academic Press, pp. 255-343.

CAMERON, L., RUTLAND, A. and BROWN, R. 2007 'Promoting children's positive intergroup attitudes towards stigmatized groups: Extended contact and multiple classification skills training', International Journal of Behavioral Development, vol. 31, no. 5, 454-466

COLE, M. 2009 'A Plethora of 'suitable enemies': British racism at the dawn of the twenty-first century', Ethnic and Racial Studies, vol. 32, 1671-1685 COMMUNITY COHESION REVEIW TEAM 2001 'Community cohesion: A report of the independent review team'. Home Office, London

DIXON, J., DURRHEIM, K. and TREDOUX, C. 2005 'Beyond the optimal strategy: A 'reality check' for the contact hypothesis', American Psychologist, vol. 60, no 7, $697-711$

ECHEBARRIA-ECHABE, A. and FERNANDEZ-GUEDE, E. 2006 'Effects of terrorism on attitudes and ideological orientation', European Journal of Social Psychology, vol. 36, no. 2, 259-65

FINNEY, N. and SIMPSON, L. 2009 'Sleepwalking into segregation? Challenging the myths about race and migration', Bristol: Polity Press GREATER LONDON AUTHORITY 2006 'Muslims in London’, Greater London Authority, London 
HUTCHISON, P. et al. 2006 'Protecting threatened identity; Sticking with the group by emphasizing ingroup heterogeneity', Personality and Social Psychology Bulletin, vol. 32 , no. $12,1620-32$

HUTCHISON, P. et al. in press 'Anxiety, outcome expectancies, and young people's willingness to engage in contact with the elderly', Educational Gerontology.

ISLAM, M. R. and HEWSTONE, M. 1993 'Dimension of contact as predictors of intergroup anxiety, perceived outgroup variability and outgroup attitudes: An integrative model', Personality and Social Psychology Bulletin, vol. 19, no. 6, 70010

LIEBKIND, K. and McALISTER, A. L. 1999 'Extended contact through peer modelling to promote tolerance in Finland', European Journal of Social Psychology, vol. 29 , no. $5,765-80$

MERSKIN, D. 2004 'The construction of Arabs as enemies: Post-September 11 discourse of George W. Bush', Mass Communication and Society, vol. 7, no. 2, 15775

NOSEK, B. A. et al. 2007 'Pervasiveness and correlates of implicit attitudes and stereotypes', European Review of Social Psychology, vol. 18, no. 1, 36-88. OSTROM, T. M. and SEDIKIDES C. 1992 'Out-group homogeneity effects in natural and minimal groups', Psychological Bulletin, vol. 112, no. 3, 536-52 PAOLINI, S et al. 2004 'Effects of direct and indirect cross-group friendships on judgements of Catholics and Protestants in Northern Ireland: The mediating role of an anxiety-reduction mechanism', Personality and Social Psychology Bulletin, vol. 30, no. $6,770-86$

PARK, B. and JUDD, C. M. 1990 'Measures and models of perceived group variability', Journal of Personality and Social Psychology, vol. 59, no. 2, 173-91 
PARK, J., FELIX, K. and LEE, G. 2007 'Implicit attitudes toward Arab-Muslims and the moderating effects of social information', Basic and Applied Social Psychology, vol. 29, no. 1, 35-45

PETTIGREW, T. F. 1998 'Intergroup contact: Theory, research and new perspectives', Annual Review of Psychology, vol. 49, 65-85

PETTIGREW, T. F. and TROPP, L. R. 2006 'A meta-analytic test of intergroup contact theory', Journal of Personality and Social Psychology, vol. 90, no. 5, 751-83 PETTIGREW, T. F. and TROPP, L. R. 2008 'How does intergroup contact reduce prejudice? Meta-analytic tests of three mediators', European Journal of Social Psychology, vol. 38, no. 6, 922-34

PHILLIPS, D. 2006 'Parallel lives? Challenging discourses of British Muslim selfsegregation', Environment and Planning D: Society and Space, vol. 24, 25-40 PLANT, E. A. and Devine, P. 2003 'The antecedents and implications of interracial anxiety', Personality and Social Psychology Bulletin, vol. 29, no. 6, 790-801 PREACHER, K. J. and LEONARDELLI, G. L. 2001 'Calculation for the Sobel test: An interactive calculation tool for mediation tests', Retrieved January 292009 from: http://www.psych.ku.edu/preacher/sobel/sobel.htm QUATTRONE, G. A. and JONES, E. E. 1980 'The perception of variability within in-groups and out-groups: Implications for the law of small numbers', Journal of Personality and Social Psychology, vol. 38, no. 1, 141-52

SHERIDAN, L. P. 2006 'Islamophobia pre- and post-September 11th, 2001', Journal of Interpersonal Violence, vol. 21, no. 3, 317-36

SHERIDAN, L. P. and GILLET, R. 2005 'Major world events and discrimination', Asian Journal of Social Psychology, vol. 8, no. 2, 191-97 
STEPHAN, W. G. and RENFRO, C. L. 2002, 'The role of threat in intergroup relations', in D. M. Mackie and E. R. Smith (eds), From prejudice to intergroup emotions: Differentiated reactions to social groups, New York, NY: Psychology Press, pp. 191-207

STEPHAN, W. G. and STEPHAN, C. W. 1985 'Intergroup anxiety', Journal of Social Issues, vol. 41, no. 3, 157-76

SUTTON, S. 1998 'Predicting and explaining intentions and behavior: How well are we doing?', Journal of Applied Social Psychology, vol. 28, no. 15, 1317-38

TAM, T. et al. 2006 'Intergroup contact and grandparent-grandchild communication: The effects of self-disclosure on implicit and explicit biases against older people', Group Processes \& Intergroup Relations, vol. 9, no. 3, 413-30

TAM, T. et al. 2009 'Intergroup trust in Northern Ireland', Personality and Social Psychology Bulletin, vol. 35, no. 1, 45-59

TURNER, R. N., CRISP, R. J. And LAMBERT, E. 2007 'Imagining intergroup contact can improve intergroup attitudes', Group Processes and Intergroup Relations, vol. 14 , no. $4,427-441$

TURNER, R. N., HEWSTONE, M. and VOCI, A. 2007 'Reducing explicit and implicit outgroup prejudice via direct and extended contact: The mediating role of self-disclosure and intergroup anxiety', Journal of Personality and Social Psychology, vol. 93, no. 3, 369-88

TURNER, R. N. et al. 2008 'A test of the extended contact hypothesis: The mediating role of intergroup anxiety, perceived ingroup and outgroup norms, and inclusion of the outgroup in the self', Journal of Personality and Social Psychology, vol. 95 , no. $4,843-60$ 
VIKI, G. T. et al. 2006 'Race and willingness to cooperate with the police: The role of quality of contact, attitudes towards the behaviour and subjective norms', British Journal of Social Psychology, vol. 45, no. 2, 285-302

VOCI, A. and HEWSTONE, M. 2003 'Intergroup contact and prejudice toward immigrants in Italy: The meditational role of anxiety and the moderational role of group salience', Group Processes and Intergroup Relations, vol. 6, no. 1, 37-51 WILDER, D. A. and SHAPIRO, P. 1989 'Effects of anxiety on impression formation in a group context: An anxiety-assimilation hypothesis' Journal of Experimental Social Psychology, vol. 25, no. 6, 481-99

WRIGHT, S. C. et al. 1997 'The extended contact effect: Knowledge of cross-group friendships and prejudice', Journal of Personality and Social Psychology, vol. 73, no. $1,73-90$ 


\section{Footnotes}

${ }^{1}$ Although the present research is framed in terms of prejudice against Muslims, individuals and groups who are not Muslim but who are wrongly identified as such (e.g., through perceptions of ethnicity, national heritage or language) are also increasingly becoming the recipients of prejudiced attitudes and behaviour.

${ }^{2}$ The term 'Arab' is distinct from the religious identity of 'Muslim'. However, attacks on Arabs often reflect the assumption that they are Muslim (see Footnote 1). This is despite considerable religious diversity in many Arabic countries, and the far greater numbers of Muslims from non-Arabic ethnic and geographical areas.

${ }^{3}$ We did not collect data on the participants' race, ethnicity or nationality in either study because previous research suggests that these variables have no influence on attitudes towards Muslims (e.g., Park et al. 2007).

${ }^{4}$ Two of the data collectors were Black and two of the data collectors were White. Race of data collectors had no impact on any of the analyses.

${ }^{5}$ We report results of mediation analysis for the multiplicative index of intergroup contact, although intergroup anxiety also mediated the associations between contact quantity and quality and the various outcome measures.

${ }^{6}$ Two of the data collectors were White and one of the data collectors was Black. As in Study 1, race of data collectors had no impact on any of the analyses.

${ }^{7}$ As in Study 1, intergroup anxiety also mediated the associations between contact quantity and quality on the various outcome measures. 
$\underline{\text { Table } 1}$

Means, standard deviations, and correlations among the variables (Study 1)

\begin{tabular}{|c|c|c|c|c|c|c|c|c|c|}
\hline \multirow[b]{2}{*}{ Variable } & \multicolumn{9}{|c|}{ Variable } \\
\hline & $\mathrm{M}$ & SD & 1 & 2 & 3 & 4 & 5 & 6 & 7 \\
\hline 1. Contact quantity & 3.36 & 4.55 & - & .13 & $.97 * * *$ & $.36 * *$ & $.28 *$ & $.33 * *$ & $-.31 *$ \\
\hline 2. Contact quality & 3.76 & 0.99 & & - & $.27^{*}$ & $.33 * *$ & $.40 * *$ & $.49 * * *$ & $-.56 * * *$ \\
\hline 3. Intergroup contact & 13.19 & 17.43 & & & - & $.42 * * *$ & $.32 * *$ & $.40 * *$ & $-.36 * *$ \\
\hline 4. Outgroup attitudes & 3.33 & 0.79 & & & & - & $.39 * *$ & $.57 * * *$ & $-.49 * * *$ \\
\hline 5. Perceived outgroup variability & 2.87 & 0.84 & & & & & - & $.55 * * *$ & $-.49 * * *$ \\
\hline 6. Intergroup behavioural intentions & 3.09 & 0.87 & & & & & & - & $-.71 * * *$ \\
\hline 7. Intergroup anxiety & 2.28 & 1.02 & & & & & & & - \\
\hline
\end{tabular}

Note. All measures used 5-point scales except contact quantity, which required respondents to write a number to indicate how much contact and extended contact they had with Muslims. 
$\underline{\text { Table } 2}$

Results of mediation analyses (Study 1)

\begin{tabular}{lcc}
\hline & $\begin{array}{c}\text { Intergroup contact } \\
\text { (entered with intergroup } \\
\text { anxiety) }\end{array}$ & $\begin{array}{c}\text { Intergroup anxiety } \\
\text { (entered with intergroup } \\
\text { contact) }\end{array}$ \\
\hline Dependent variable & $.28^{*}$ & $-.39^{* *}$ \\
Outgroup attitudes & .16 & $-.43^{* *}$ \\
Perceived outgroup variability & .17 & $-.65^{* * *}$ \\
Intergroup behavioural intentions & &
\end{tabular}

Note. Figures are standardized beta coefficients. 
$\underline{\text { Table } 3}$

Means, standard deviations, and correlations among the variables (Study 3)

\begin{tabular}{|c|c|c|c|c|c|c|c|c|c|c|}
\hline$+\gamma$ & & & & & Variable & & & & & \\
\hline Variable & $\mathrm{M}$ & SD & 1 & 2 & 3 & 4 & 5 & 6 & 7 & 8 \\
\hline 1. Contact quantity & 4.67 & 6.47 & - & $.34 * *$ & $.97 * * *$ & $.54 * * *$ & $.37 * *$ & $.20 \dagger$ & $.30 * *$ & $-.31 * *$ \\
\hline 2. Contact quality & 3.65 & 0.99 & & 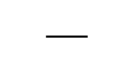 & $.43 * * *$ & $.44 * * *$ & $.59 * * *$ & $.54 * * *$ & $.53 * * *$ & $-.53 * * *$ \\
\hline 3. Intergroup contact & 19.20 & 28.54 & & & - & $.55 * * *$ & $.42 * * *$ & $.25 *$ & $.35 * *$ & $-.31 * *$ \\
\hline 4. Extended contact & 3.48 & 4.24 & & & & - & $.37 * *$ & $.30 * *$ & $.41 * *$ & $-.38 * *$ \\
\hline 5. Outgroup attitudes & 3.46 & 0.83 & & & & & - & $.43 * * *$ & $.71 * * *$ & $-.63^{* * *}$ \\
\hline 6. Perceived outgroup variability & 4.01 & 0.85 & & & & & & - & $.51 * * *$ & $-.54 * * *$ \\
\hline 7. Intergroup behavioural intentions & 3.26 & 0.77 & & & & & & & - & $.57 * * *$ \\
\hline 8. Intergroup anxiety & 3.94 & 0.91 & & & & & & & & - \\
\hline
\end{tabular}

$* p<.05, * * p<.01, * * * p<.001, \dagger p=.06$

Note. All measures used 5-point scales except contact quantity and extended contact, which required respondents to write a number to indicate how much contact and extended contact they had with Muslims. 
$\underline{\text { Table } 4}$

Results of mediation analyses (Study 2)

\begin{tabular}{|c|c|c|c|c|}
\hline & \multicolumn{2}{|c|}{ Intergroup contact } & \multicolumn{2}{|c|}{ Extended contact } \\
\hline & $\begin{array}{c}\text { Intergroup contact } \\
\text { (entered with intergroup } \\
\text { anxiety) }\end{array}$ & $\begin{array}{c}\text { Intergroup anxiety } \\
\text { (entered with intergroup } \\
\text { contact) } \\
\end{array}$ & $\begin{array}{c}\text { Extended contact } \\
\text { (entered with intergroup } \\
\text { anxiety) } \\
\end{array}$ & $\begin{array}{c}\text { Intergroup anxiety } \\
\text { (entered with extended } \\
\text { contact) }\end{array}$ \\
\hline \multicolumn{5}{|l|}{ Dependent variable } \\
\hline Outgroup attitudes & $.25^{*}$ & $-.56^{* *}$ & .15 & $-.57 * *$ \\
\hline Perceived outgroup variability & .10 & $-.51 * *>$ & .10 & $-.50 * *$ \\
\hline Intergroup behavioural intentions & .19 & $-.52 * *$ & $.22^{\dagger}$ & $-.49 * *$ \\
\hline
\end{tabular}

$* p<.05, * * p<.001,{ }^{\dagger} p=.054$.

Note. Figures are standardized beta coefficients. 
PAUL HUTCHISON is a Senior Lecturer in the School of Psychology at London

Metropolitan University.

ADDRESS: School of Psychology, London Metropolitan University, Calcutta House, Old

Castle Street, London, E1 7NY, UK.

Email: p.hutchison@1ondonmet.ac.uk

HARRIET ROSENTHAL is a Lecturer in the Psychology Department at the University of Durham.

ADDRESS: Department of Psychology, Durham University, Science Site, South Road, Durham, DH1 3LE, UK.

Email: h.e.s.rosenthal@durham.ac.uk

\section{$\underline{\text { Acknowledgements }}$}

The authors are grateful to Martin Bulmer and two anonymous reviewers for feedback on an earlier version of this article. 